\title{
Relationships between FSH patterns and follicular dynamics and the temporal associations among hormones in natural and $\mathrm{GnRH}$-induced gonadotropin surges in heifers
}

\author{
J M Haughian, O J Ginther ${ }^{1}$, K Kot ${ }^{1}$ and M C Wiltbank \\ Department of Dairy Science, 1675 Observatory Drive and ${ }^{1}$ Department of Animal Health and Biomedical \\ Sciences, University of Wisconsin, Madison, Wisconsin 53706, USA \\ Correspondence should be addressed to M C Wiltbank; Email: wiltbank@calshp.cals.wisc.edu
}

\begin{abstract}
Preovulatory LH and FSH surges and the subsequent periovulatory FSH surge were studied in heifers treated with a single injection of $\mathrm{GnRH}(100 \mu \mathrm{g}, n=6)$ or saline $(n=7)$. Blood samples were collected every hour from $6 \mathrm{~h}$ before treatment until $12 \mathrm{~h}$ after the largest follicle reached $\geq 8.5 \mathrm{~mm}$ (expected beginning of follicular deviation). The GnRH-induced preovulatory LH and FSH surges were higher at the peak and shorter in duration than in controls, but the area under the curve was not different between groups. The profiles of the preovulatory LH and FSH surges were similar within each treatment group, suggesting that the two surges involved a common GnRH-dependent mechanism. Concentrations of FSH in controls at the nadir before the preovulatory surge and at the beginning and end of the periovulatory surge were not significantly different among the three nadirs. A relationship between variability in the periovulatory $\mathrm{FSH}$ surge and number of $5.0 \mathrm{~mm}$ follicles was shown by lower FSH concentrations during 12-48 $\mathrm{h}$ after the beginning of the surge in heifers with more follicles $(11.0 \pm 1.0$ follicles (mean \pm S.E.M.) $n=7$ ) than in heifers with fewer follicles $(5.7 \pm 0.4, n=6)$. This result was attributed to increased FSH suppression from increased numbers of follicles reaching $5.0 \mathrm{~mm}$. Grouping of heifers into those with longer vs shorter intervals from a $4.5 \mathrm{~mm}$ to an $\mathbf{8 . 5} \mathrm{mm}$ largest follicle did not disclose any relationship between length of the interval and FSH characteristics (e.g. profile of surge, area under curve, FSH concentrations at specific events). The hypothesis of a relationship between variation in the periovulatory FSH surge and variation in follicular dynamics was supported for the number of $5.0 \mathrm{~mm}$ follicles but not for the hour the largest follicle reached $8.5 \mathrm{~mm}$. Thus, the expected time of follicle deviation was not altered by the extensive variation in the wave-stimulating $\mathrm{FSH}$ surge.

Reproduction (2004) 127 23-33
\end{abstract}

\section{Introduction}

In cattle, a gonadotropin-releasing hormone (GnRH) surge stimulates the release of the preovulatory luteinizing hormone (LH) surge (Yoshioka et al. 2001). A surge in circulating follicle-stimulating hormone (FSH) concentrations occurs at the time of the LH surge, but the profiles of the surges apparently have not been compared statistically between the two gonadotropins; similarity would indicate that the two surges result from a similar or the same mechanism. The peak of the preovulatory surges of $\mathrm{LH}$ and $\mathrm{FSH}$ occurs a little more than one day before ovulation. At approximately the peak of the preovulatory $\mathrm{LH}$ and $\mathrm{FSH}$ surges, circulating concentrations of estradiol begin to decline, and toward the end of the estradiol decline another surge in FSH begins (Taya et al. 1991, Bergfelt et al. 1997, Kulick et al. 1999). The FSH surge that occurs after the preovulatory surge has been termed the second or secondary FSH surge (Turzillo \& Fortune 1990, Bergfelt et al. 1997). We will use the term periovulatory FSH surge or increase as in a previous report (Austin et al. 2002) for the following reasons: (i) the surge encompasses ovulation in individuals; (ii) the term secondary does not reflect the physiological importance of the surge in initiating a follicular wave; and (iii) the term obviates confusion with the use of second FSH surge (Kulick et al. 2001) for the second follicular wave.

Within 20 min of treatment during the follicular phase, a single injection of $100 \mu \mathrm{g}$ GnRH stimulates a surge of LH followed by ovulation of the dominant follicle (Lucy \& Stevenson 1986, Pursley et al. 1995). It appears from inspection of data profiles that the preovulatory surge of $\mathrm{LH}$ induced by a $\mathrm{GnRH}$ injection is shorter than the natural preovulatory LH surge, but critical studies are lacking. There is an FSH surge associated with the LH surge 
following the $\mathrm{GnRH}$ treatment. The induced FSH surge has been studied during the luteal phase (Chenault et al. 1990) but has received limited consideration during the follicular phase or the time when GnRH is used in synchronization protocols. In one study (Bodensteiner et al. 1996), comparisons of the natural and induced FSH surges were precluded because the preovulatory and periovulatory FSH surges were not delineated adequately as separate surges by the $8 \mathrm{~h}$ interval between blood sampling. It is not known if the $\mathrm{GnRH}$-induced preovulatory $\mathrm{LH}$ and $\mathrm{FSH}$ surges affect the shape of the periovulatory FSH surge or the associated follicles. Bodensteiner et al. (1996) reported that inducing ovulation with $\mathrm{GnRH}$ increased the number of $5 \mathrm{~mm}$ follicles in the periovulatory follicular wave, indirectly suggesting that the periovulatory FSH surge may have been altered by the exogenous $\mathrm{GnRH}$.

The degree of separation between the preovulatory and periovulatory surges in the profiles of mean FSH concentrations varies considerably among reports, primarily because of differences in the length of the interval between blood samples. Somewhat analogous to detecting the peak of the preovulatory surge, detecting the nadir requires frequent sampling. In studies with sampling at $8 \mathrm{~h}$ intervals, the mean nadir apparently was not approached (Kulick et al. 1999) or was not distinguishable (Bodensteiner et al. 1996). When blood samples were taken every 2-6h (Turzillo \& Fortune 1990, Sunderland et al. 1994, Bleach et al. 2001), the nadir did not appear to be attained consistently among studies.

Information on the relative roles of the two FSH surges in the initiation of the first follicular wave of the estrous cycle is limited, at least partly because the temporality between follicles and the intersurge nadir was obscured by the inadequate demonstration of the nadir. Results of a study involving administration of charcoal-extracted follicular fluid and sampling at $4 \mathrm{~h}$ intervals was interpreted to suggest that the periovulatory surge was important for wave initiation (Turzillo \& Fortune 1990). However, the nadir between surges in the controls was not well defined.

The periovulatory FSH surge begins to decline when the largest follicle is about $5 \mathrm{~mm}$ (for a review see Ginther et al. 2001). Follicle selection during a follicular wave involves deviation in diameters between the future dominant and subordinate follicles and begins in cattle when the largest follicle is a mean of $8.5 \mathrm{~mm}$. Mean FSH concentrations continue to decline for less than 1 day after the beginning of deviation. Studies involving minimizing or preventing the FSH decrease have indicated that a low concentration of FSH is an essential component of the deviation process. Circulating FSH concentrations encompassing deviation have been studied at $1 \mathrm{~h}$ intervals from just before the beginning of deviation but apparently no studies have been done using a similar frequency of sampling for the entire periovulatory surge. Except for the studies on follicle/FSH relationships when the largest follicle is about $4.0,5.0$ and $8.5 \mathrm{~mm}$, the functional interrelationships between the wave and surge have been given limited attention. The extent of variation in the wave-stimulating FSH surge apparently has not been studied. It is not known whether variations in FSH dynamics or shape of the surge are related to number of follicles of the wave, growth rate of follicles, or time of occurrence of deviation.

To investigate the regulation of follicular growth in the first wave of the estrous cycle we tested the following two hypotheses: Hypothesis 1 - on a temporal basis, the periovulatory surge alone accounts for the emergence of the wave; and Hypothesis 2 - variation in the periovulatory FSH surge is related to variation in the characteristics of the periovulatory follicular wave, including number of follicles in the wave, growth rate of follicles, and time of occurrence of deviation. To undertake this investigation, we measured hormones and follicular growth characteristics in normal cycles and in animals with ovulation induced by $\mathrm{GnRH}$ treatment. The $\mathrm{GnRH}$-treated group was included in an attempt to increase the variability of the periovulatory FSH surge, so that follicular response to exaggerated FSH variability would be included. Secondarily, the GnRH-treated group provided the opportunity to compare and contrast natural $\mathrm{LH}$ and $\mathrm{FSH}$ preovulatory surges with $\mathrm{GnRH}$-induced surges and the associated estradiol concentration changes.

\section{Materials and Methods \\ Treatments and data collection}

Nulliparous Holstein heifers ranging in age from 18 to 36 months and weighing $520-650 \mathrm{~kg}$ were used. The feeding program and the equipment and techniques for transrectal ultrasound scanning of ovaries and measuring follicles have been described (Ginther et al. 1999). At 5 or 6 days after the pretreatment ovulation, all heifers were administered two $25 \mathrm{mg}$ injections (12 $\mathrm{h}$ apart) of prostaglandin (PG)F2 $\alpha$ (Lutalyse; Pharmacia Corporation, Peapack, NJ, USA) to regress the corpus luteum. Thirty-six hours after the first PGF2 $\alpha$ injection, heifers were randomly assigned to be treated (i.m.) with a single injection of $100 \mu \mathrm{g}$ GnRH (Cystorelin; Merial Limited, Athens, GA, USA (GnRH group, $n=6$ ) or physiological saline as a control (saline group, $n=7$ ). Follicle development was monitored by transrectal ultrasonography every $6 \mathrm{~h}$ from the time of $\mathrm{GnRH}$ or saline treatment until ovulation and thereafter every $12 \mathrm{~h}$ until 1 day after detection of an $8.5 \mathrm{~mm}$ largest follicle. Hourly blood sampling began $6 \mathrm{~h}$ before $\mathrm{GnRH}$ or saline treatment and continued until $12 \mathrm{~h}$ after the expected beginning of follicle deviation as indicated by a largest follicle of $8.5 \mathrm{~mm}$. The duration of hourly sampling ranged from 4 to 5 days and was intended to extend from before the onset of the preovulatory LH and FSH surges until after the beginning of follicle deviation during the periovulatory FSH surge (Ginther et al. 2001). To facilitate blood sampling, an indwelling jugular catheter was used as previously described (Ginther et al. 1998). 
Table 1 Characteristics (means \pm S.E.M.) of preovulatory LH and FSH surges in heifers treated with saline $(n=7)$ or $100 \mu \mathrm{g} \mathrm{GnRH}(n=6)$.

\begin{tabular}{|c|c|c|c|c|}
\hline \multirow[b]{2}{*}{ End point } & \multicolumn{2}{|c|}{ Saline } & \multicolumn{2}{|c|}{ GnRH } \\
\hline & $\mathrm{LH}$ & $\mathrm{FSH}$ & $\mathrm{LH}$ & $\mathrm{FSH}$ \\
\hline \multicolumn{5}{|l|}{ Interval $(\mathrm{h})$} \\
\hline Treatment to onset & $15.9 \pm 2.9^{\mathrm{a}}$ & $15.6 \pm 3.2^{\mathrm{a}}$ & $0.0 \pm 0.0^{b}$ & $0.0 \pm 0.0^{b}$ \\
\hline Onset to maximum & $4.9 \pm 0.5^{\mathrm{a}}$ & $5.0 \pm 0.7^{\mathrm{a}}$ & $2.0 \pm 0.0^{\mathrm{b}}$ & $2.0 \pm 0.0^{\mathrm{b}}$ \\
\hline Onset to end & $10.4 \pm 0.7^{\mathrm{a}}$ & $11.4 \pm 0.6^{\mathrm{a}}$ & $6.8 \pm 0.3^{b}$ & $7.7 \pm 0.4^{\mathrm{b}}$ \\
\hline Maximum concentration $(\mathrm{ng} / \mathrm{ml})$ & $8.8 \pm 1.0^{\mathrm{c}}$ & $0.32 \pm 0.02^{\mathrm{e}}$ & $17.3 \pm 2.8^{\mathrm{d}}$ & $0.55 \pm 0.07^{f}$ \\
\hline Area under curve (ng) & $38.7 \pm 6.7^{\mathrm{a}}$ & $1.27 \pm 0.15^{\mathrm{b}}$ & $39.1 \pm 3.2^{\mathrm{a}}$ & $1.3 \pm 0.15^{\mathrm{b}}$ \\
\hline
\end{tabular}

${ }^{a, b}$ Means within a row with different superscripts are different $(P<0.05)$.

${ }^{\mathrm{c}, \mathrm{d}} \mathrm{LH}$ means with different superscripts are different $(P<0.05)$.

${ }^{\mathrm{e}, \mathrm{f}} \mathrm{FSH}$ means with different superscripts are different $(P<0.05)$.

Blood samples were collected into heparinized tubes and immediately refrigerated at $4{ }^{\circ} \mathrm{C}$. Within $24 \mathrm{~h}$ of collection, plasma was separated by centrifugation, decanted into storage vials and stored at $-20^{\circ} \mathrm{C}$ until assay.

\section{Hormone assays}

Plasma $\mathrm{LH}$ and FSH were measured by RIAs as previously described (Bolt \& Rollin 1983, Bolt et al. 1990) and modified for use in our laboratories (Ginther et al. 1999). Assay of LH used NIDDK-anti-oLH-1 as the primary antibody and USDA-bLH-B6 as both the standard and radiolabeled protein. Interassay and intraassay coefficient of variation (CV) values were 16.7 and $11.6 \%$, with 10 and $90 \%$ binding at 40 and $0.16 \mathrm{ng} \mathrm{LH} / \mathrm{ml}$ respectively. Assay of $\mathrm{FSH}$ used NIDDK-anti-oFSH-I-2 as the primary antibody and USDA-bFSH-I-2 as the standard and radiolabeled protein. Interassay and intraassay CV values were 11.2 and $5.3 \%$, with 10 and $90 \%$ binding at 5.00 and $0.03 \mathrm{ng} \mathrm{FSH} / \mathrm{ml}$ respectively. Plasma estradiol concentrations were measured using modifications of a commercial estradiol RIA kit (Third Generation Estradiol Assay Kit; Diagnostics Systems Laboratories Inc., Webster, TX, USA) previously verified for use in cattle (Kulick et al. 1999). The interassay and intraassay CV values were 17.6 and $14.6 \%$ respectively, with 10 and $90 \%$ binding at 40.0 and $0.3 \mathrm{pg}$ estradiol $/ \mathrm{ml}$ respectively.

\section{Definitions}

The hours of onset and end of preovulatory surges were calculated and used for comparisons between surges and treatments and for studying the hours of events and area under the curve. The onset (or end) of the preovulatory LH and FSH surges were defined as occurring at the sample hour before two consecutive samples with concentrations above (or below) the average hormone concentration of the first six pretreatment samples plus $2 \times$ s.D. of the six pretreatment samples. The nadir preceding the natural preovulatory LH surge was obscured in some heifers and was not used as a reference point. For the preovulatory FSH surge, the nadir (Nadir 1) in the $\mathrm{GnRH}$-treatment heifers occurred at the hour of treatment. Nadir 1 for the natural
FSH surge in control heifers was the lowest value preceding an apparent progressive increase in concentrations. The discrete gonadotropin end points that were used in the comparisons between saline and $\mathrm{GnRH}$ groups for the preovulatory $\mathrm{LH}$ and FSH surges (see Table 1) and the periovulatory FSH surge (see Table 2) are shown.

The onset of the periovulatory FSH surge was assigned to the hour with the lowest value (Nadir 2) between the two FSH surges that was followed by a progressive increase in concentrations. The hour of a peak value was not assignable to some of the periovulatory surges because of irregularities or fluctuations. Therefore, the value at the

Table 2 Characteristics (means \pm S.E.M.) of periovulatory FSH surge and follicular wave in heifers treated with saline $(n=7)$ or $\mathrm{GnRH}$ $(n=6)$.

\begin{tabular}{|c|c|c|}
\hline End point & Saline & GnRH \\
\hline \multicolumn{3}{|l|}{ Interval (h) } \\
\hline Peak of LH to Nadir $2^{*}$ & $10.4 \pm 0.7^{\mathrm{a}}$ & $7.2 \pm 0.5^{\mathrm{b}}$ \\
\hline Nadir 2 to $4.5 \mathrm{~mm} \mathrm{~F}^{+}$ & $13.9 \pm 1.6^{\mathrm{a}}$ & $8.7 \pm 2.0^{\mathrm{b}}$ \\
\hline Nadir 2 to peak FSH & $14.1 \pm 0.7$ & $15.5 \pm 1.2$ \\
\hline Nadir 2 to $8.5 \mathrm{~mm}$ F1 & $50.1 \pm 2.3$ & $48.0 \pm 4.6$ \\
\hline $4.5 \mathrm{~mm}$ to $8.5 \mathrm{~mm} \mathrm{~F} 1$ & $36.3 \pm 2.0$ & $39.3 \pm 4.0$ \\
\hline Peak FSH to $8.5 \mathrm{~mm} \mathrm{F1}$ & $36.0 \pm 2.7$ & $32.5 \pm 5.1$ \\
\hline Beginning of decline to $8.5 \mathrm{~mm} \mathrm{~F} 1$ & $28.9 \pm 4.0$ & $29.7 \pm 4.3$ \\
\hline Nadir 2 to Nadir $3^{*}$ & $48.1 \pm 5.7$ & $46.0 \pm 5.7$ \\
\hline \multicolumn{3}{|l|}{ FSH concentrations $(\mathrm{ng} / \mathrm{ml})$ at } \\
\hline $\begin{array}{l}\text { Nadir } 2 \\
4.5 \mathrm{~mm} \text { F1 }\end{array}$ & $\begin{array}{l}0.07 \pm 0.01^{\mathrm{d}} \\
0.25 \pm 0.01\end{array}$ & $\begin{array}{l}0.11 \pm 0.01^{\circ} \\
0.22 \pm 0.04\end{array}$ \\
\hline Peak FSH & $0.34 \pm 0.03$ & $0.36 \pm 0.05$ \\
\hline $8.5 \mathrm{~mm} \mathrm{F1}$ & $0.18 \pm 0.03$ & $0.17 \pm 0.02$ \\
\hline Nadir 3 & $0.11 \pm 0.01$ & $0.12 \pm 0.01$ \\
\hline Area under curve & $10.7 \pm 1.7$ & $11.7 \pm 3.0$ \\
\hline \multicolumn{3}{|l|}{ Rate of change (ng/10 h) } \\
\hline Nadir 2 to peak FSH & $0.18 \pm 0.02$ & $0.16 \pm 0.02$ \\
\hline Peak FSH to $8.5 \mathrm{~mm} \mathrm{F1}$ & $0.07 \pm 0.02$ & $0.07 \pm 0.02$ \\
\hline \multicolumn{3}{|l|}{ Rate of change (mm/10 h) } \\
\hline $4.5 \mathrm{~mm}$ to $8.5 \mathrm{~mm} \mathrm{~F} 1$ & $1.1 \pm 0.1$ & $1.1 \pm 0.1$ \\
\hline No. of $5.0 \mathrm{~mm}$ follicles & $8.3 \pm 1.0$ & $8.8 \pm 1.8$ \\
\hline
\end{tabular}


end of an apparent progressive increase was designated the peak as shown in Fig. 1. The beginning of a decrease in the FSH surge was the hour with a higher concentration than for all subsequent hours (Fig. 1). The end of the periovulatory surge was based on the lowest value (Nadir 3) between the defined peak and the end of the bloodsampling period. A comparison of the concentrations among the three nadirs (Nadirs 1, 2, 3) was made in the controls.

Fluctuations or surges superimposed on the hourly circulating concentrations of the periovulatory FSH surge in individuals beginning after the peak and before an $8.5 \mathrm{~mm}$ F1 were differentiated from variation due to extraneous factors (e.g. variation in assaying technique) as described (Fitzgerald et al. 1985). (See below for definition of F1 and F2.) The CV of the values composing the ascending and descending portions of the suspected fluctuation had to be at least 2.5 times higher than the mean intraassay
$\mathrm{CV}$ to be defined as a fluctuation superimposed on the periovulatory surge. In addition, a superimposed fluctuation had to include at least one value between the lowest and highest values for each portion of the surge that preceded and followed the maximal value.

The two follicles in the periovulatory follicular wave that achieved the largest and second largest maximal diameters during the examination period were designated F1 and F2. The growth of F1 was characterized by linear regression analyses for individuals, extending from the highest value that was $<4.5 \mathrm{~mm}$ to the lowest value that was $>8.5 \mathrm{~mm}$. A linear increase in diameter of $\mathrm{F} 1$ has been shown (Ginther et al. 2001). The hour that the follicle reached $4.5 \mathrm{~mm}$ and $8.5 \mathrm{~mm}$ was determined from each linear regression line, and the resulting interval was used to represent the growth rate of $\mathrm{F} 1$. The linear regression line was used to determine $\mathrm{F} 1$ diameter at the hour of designated events during the FSH surge.
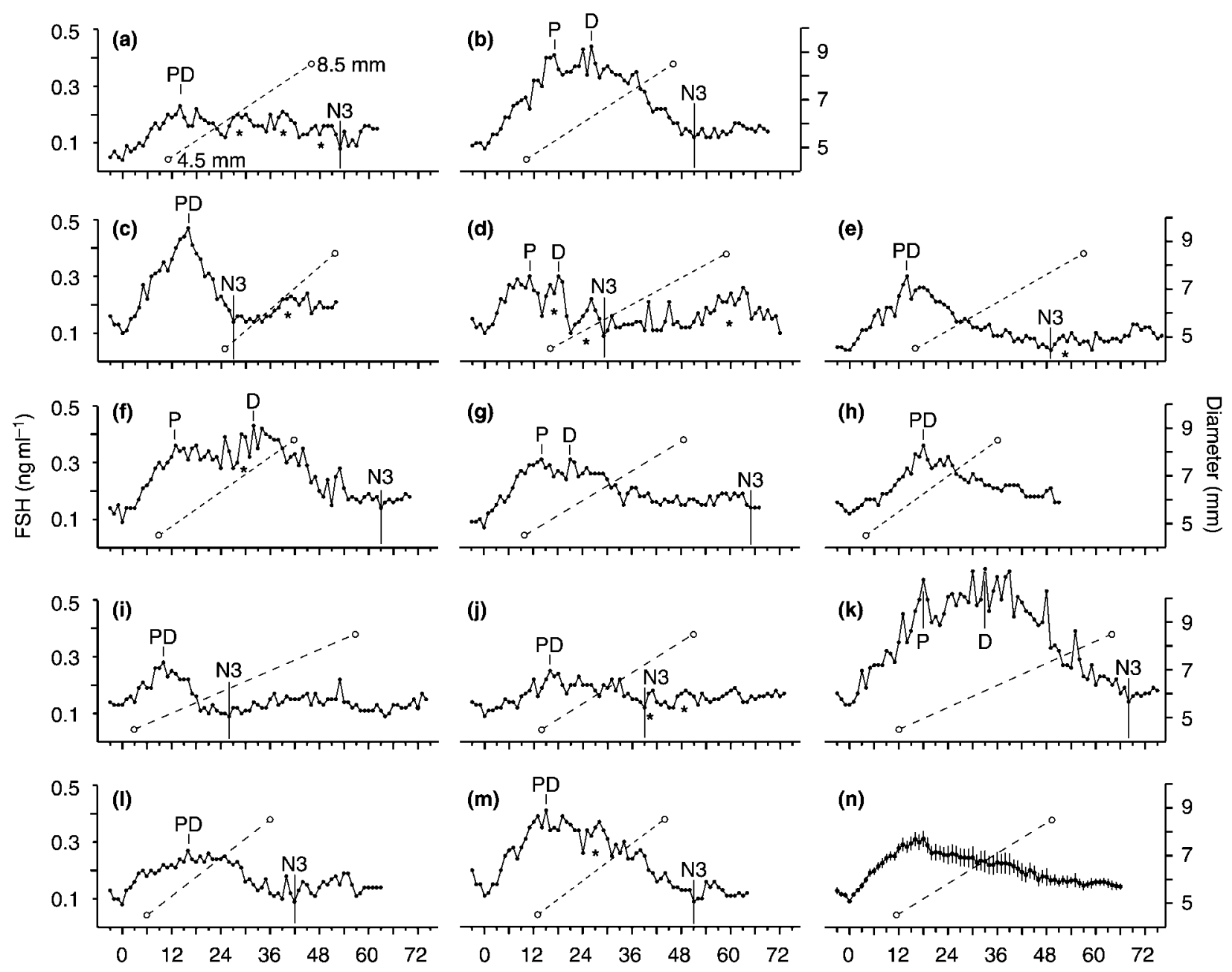

Hours from beginning of periovulatory FSH surge

Figure 1 Periovulatory FSH surges in individual heifers $(a-m)$ and for the mean \pm S.E.M. $(n) ;(a-g)$ are for saline-treated heifers and $(h-m)$ are for $\mathrm{GnRH}$-treated heifers. The broken line represents the growth of the largest follicle, extending from 4.5 to $8.5 \mathrm{~mm}$ as taken from the linear regression line. Note the extensive variation in the FSH profiles. $\mathrm{P}=$ defined peak of the surge. $\mathrm{D}=$ beginning of the FSH decline. $\mathrm{N} 3=\mathrm{Nadir} 3$ or lowest value between the peak and end of data. *Significant fluctuation superimposed on the periovulatory surge. 


\section{Normalizations and follicle groups}

Multiple normalization points relating to different $\mathrm{FSH}$ and follicle events were used. Concentrations of LH, FSH and estradiol associated with the preovulatory gonadotropin surges for each heifer were normalized to the hour of the peak concentration of the LH surge. Data for the periovulatory FSH surge were normalized to Nadir 2 (nadir between the two surges). The LH, FSH and estradiol data associated with the periovulatory FSH surge were normalized to the defined peak of the FSH surge to assess the temporal relationships before and after the peak. An F1 diameter of $8.5 \mathrm{~mm}$ was used to normalize to the expected beginning of follicle deviation, based on previous determinations in several studies that used the same operator and similar heifers (Ginther et al. 2001). Expected deviation was used rather than observed deviation because in some heifers the experiment ended before the dominant follicle was identifiable. The actual diameters taken at $12 \mathrm{~h}$ intervals normalized to deviation and not the regression lines were used for illustrating the growth profiles of F1 and F2.

The relationships between the dynamics of the periovulatory FSH surge and the dynamics of the periovulatory follicular wave were studied by grouping each of two follicle characteristics into heifers with high vs low values. This approach was used, rather than correlation analyses, so that the variation in the periovulatory FSH surge could be examined relative to different follicle outcomes, as required for testing Hypothesis 2. The follicular characteristics were grouped so that approximately half of the observations would be in each group, but also considering the most pronounced point of separation between groups. The follicular characteristics (high and low groups respectively) were number of $5.0 \mathrm{~mm}$ follicles $(11.0 \pm 1.0$, $n=7 ; 5.7 \pm 0.2, n=6$ ) and length of interval from a 4.5 to $8.5 \mathrm{~mm} \mathrm{F1}$ as determined from the linear regression lines (42.1 $\pm 2.6 \mathrm{~h}, n=8 ; 30.6 \pm 1.0 \mathrm{~h}, n=5)$. Number of follicles in a wave was based on follicles that attained a diameter of $5.0 \mathrm{~mm}$. The shape of the FSH surge (main effects of group and hour and the interaction) was compared between follicle groups. In addition, the follicle groups were compared using the discrete $\mathrm{FSH}$ end points shown in Table 3 . The relationships between the length of the interval from Nadir 2 to an $8.5 \mathrm{~mm} \mathrm{F1}$ and the presence of significant fluctuations that were superimposed on the periovulatory $\mathrm{FSH}$ surge were examined by comparing heifers with $(n=7)$ and without $(n=6)$ such fluctuations.

\section{Statistical analyses}

Student's $t$-test was used to determine differences between groups for discrete variables such as surge duration and hours to ovulation. Mean values are given \pm S.E.M. The MIXED procedure of the Statistical Analysis Systems (SAS 1998) was used to compare the main effects of group (GnRH vs saline; high vs low values) and hour and group by hour interaction on repeated measurements for plasma LH, FSH and estradiol concentrations and follicle diameter. The area under the curve of $\mathrm{LH}$ and FSH surges

Table 3 Effects (means \pm S.E.M.) of follicle characteristics in heifers with high vs low values for number of follicles and length of interval from $4.5 \mathrm{~mm}$ to $8.5 \mathrm{~mm} \mathrm{~F}^{*}$.

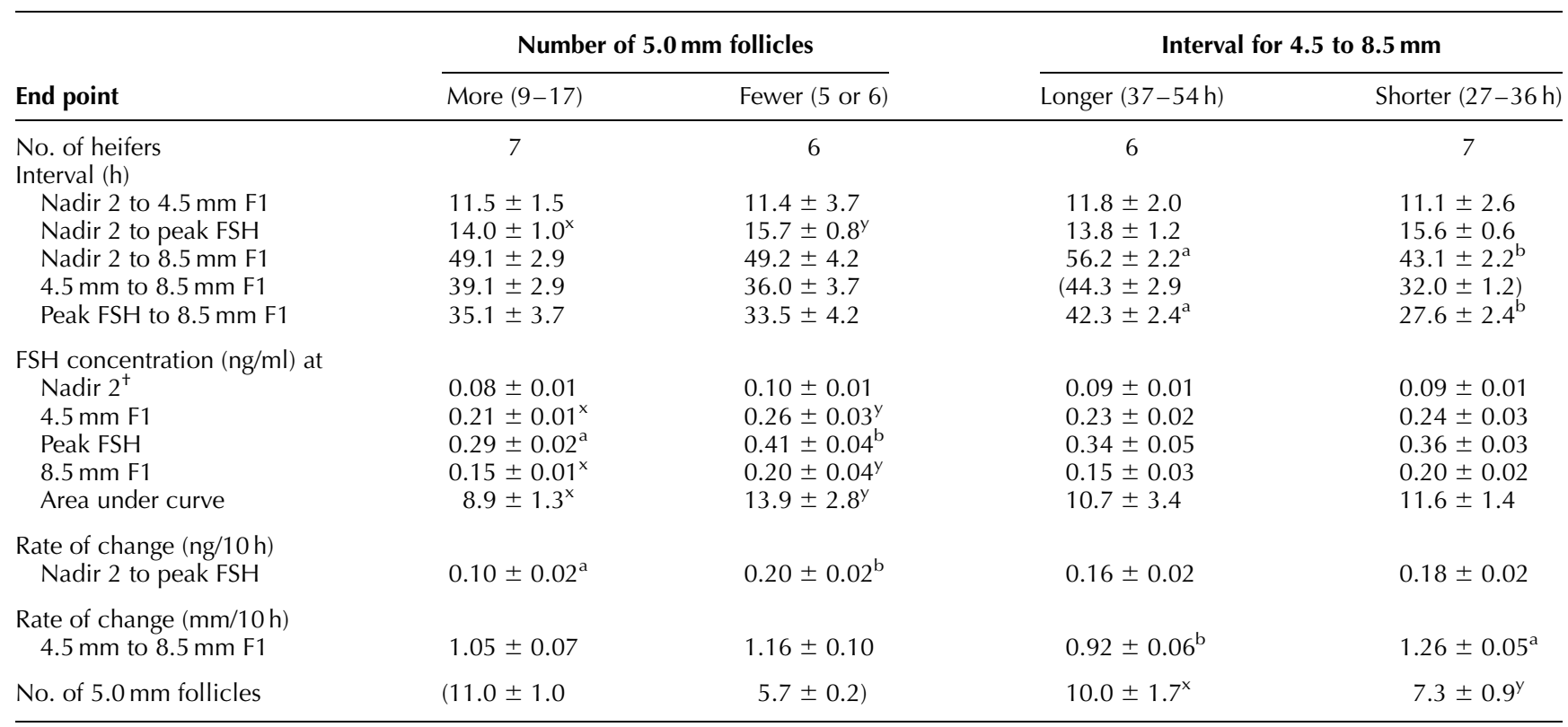

${ }_{a, b, x, y}$ Within a row and a follicle characteristic, excluding data in parentheses, means with different superscripts are different $\left({ }^{a, b} P<0.05\right)$ or approach a difference $\left.{ }^{x, y} P<0.1\right)$.

${ }^{*} \mathrm{~F} 1$ is largest follicle.

${ }^{+}$Nadir 2 is the beginning of the periovulatory FSH surge. 
was evaluated by the integration of the concentration profiles, using the EXPAND procedure of SAS (1998). Comparisons of least squares means in SAS were performed using the Tukey adjustment. A probability of $P \leq 0.05$ was considered to be significant, and probabilities between $P>0.05$ and $P<0.10$ indicated that a difference approached significance.

\section{Results}

\section{GnRH-induced vs natural preovulatory $\mathrm{LH}$ and $\mathrm{FSH}$ surges}

Every heifer displayed distinct preovulatory $\mathrm{LH}$ and $\mathrm{FSH}$ surges. The characteristics of the $\mathrm{LH}$ and FSH surges in the $\mathrm{GnRH}-$ and saline-treated groups (Table 1) and the mean profiles for $\mathrm{LH}, \mathrm{FSH}$ and estradiol normalized to the peak of the LH surge (Fig. 2) are shown. For each gonadotropin,
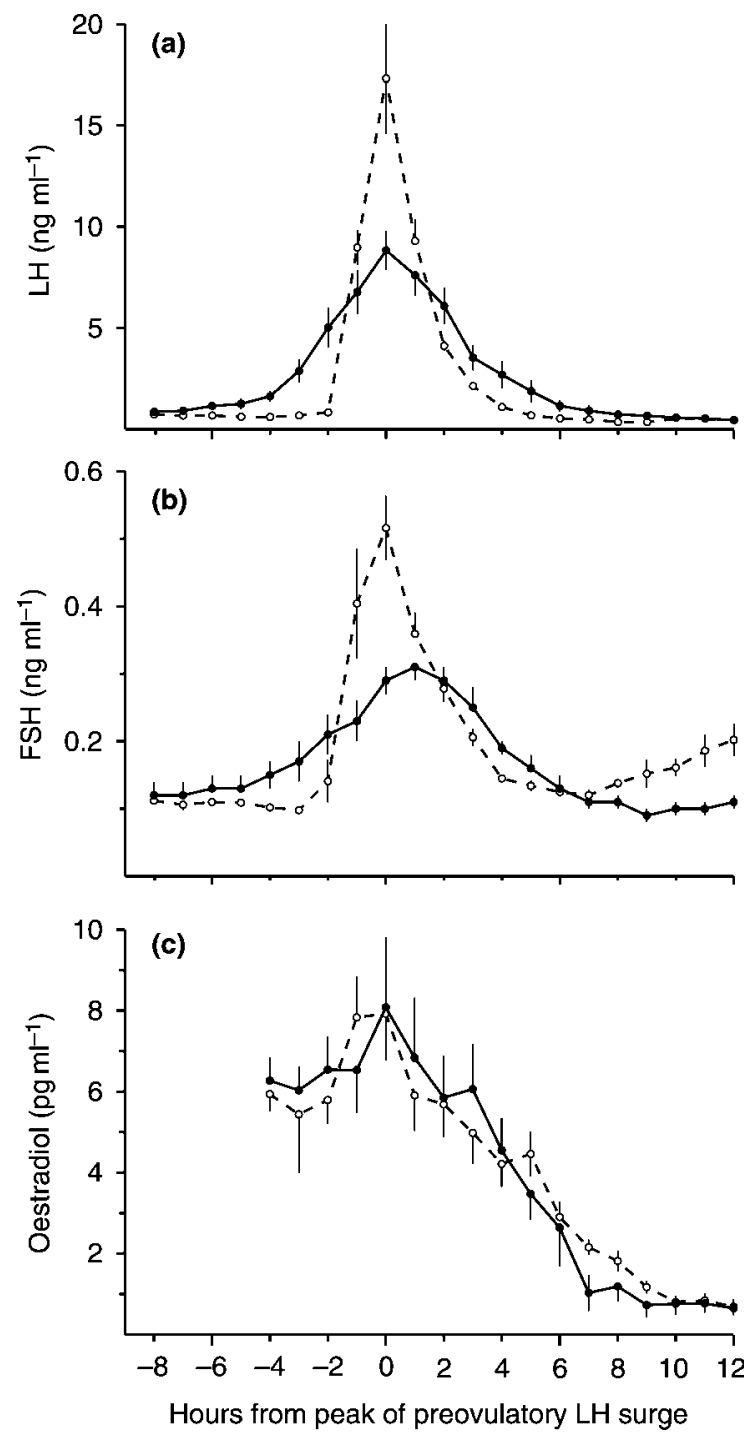

Figure 2 Concentrations (means \pm S.E.M.) for the preovulatory LH (a) and FSH (b) surges and for estradiol (c) normalized to the peak of the LH surge for saline- $(\bullet, n=7)$ and $\mathrm{GnRH}-(0, n=6)$ treated heifers. an interaction of day and group $(P<0.0001)$ reflected a shorter interval from onset to maximal concentration, higher maximal concentration, and shorter interval from onset to end of the surge in the GnRH group (Table 1 ). A significant $(P<0.0001)$ effect of hour for estradiol concentration without an effect of group or an interaction reflected a decline in concentrations beginning at the peak of the gonadotropin surges (Fig. 2).

\section{Periovulatory FSH surge}

The hour effect for the periovulatory FSH surge was significant (Fig. 3; $P<0.0001$ ), but the difference between treatment groups and the interaction of hour and group were not. The variation in the FSH profiles among surges was considerable, including significant fluctuations superimposed on the surge beginning after the defined peak and before an $8.5 \mathrm{~mm} \mathrm{~F} 1$ in 7 of 13 heifers (Fig. 1a, C-g and $\mathrm{j}$ ). A nadir in FSH concentrations between the end of the preovulatory FSH surge and onset of the periovulatory FSH surge (Nadir 2) was evident in each heifer (Fig. 1) and in the mean for each treatment group (Fig. 3). There were no significant differences in concentrations of FSH in the controls among Nadirs 1,2 and $3(0.10 \pm 0.01$, $0.07 \pm 0.01$ and $0.10 \pm 0.0 \mathrm{ng} / \mathrm{ml}$ respectively). Characteristics of the FSH surge and follicular wave for each treatment group are shown in Table 2. Additionally, the interval between the calculated end of the preovulatory FSH surge and the calculated onset of the periovulatory FSH surge was shorter $(P<0.01)$ in the $\mathrm{GnRH}$ group $(2.8 \pm 0.7 \mathrm{~h})$ than in the saline group $(6.1 \pm 0.7 \mathrm{~h})$.

There were no group differences between treatment groups in the profiles of $\mathrm{LH}, \mathrm{FSH}$ or estradiol concentrations normalized to the peak of the periovulatory FSH surge or for any of the discrete FSH characteristics, except for the higher concentration at Nadir 2 in the GnRH group. Data for the periovulatory FSH surge were combined for the two groups to study the relationships among hormones and follicles; combining groups was done because the anticipated effect of $\mathrm{GnRH}$ on variability of

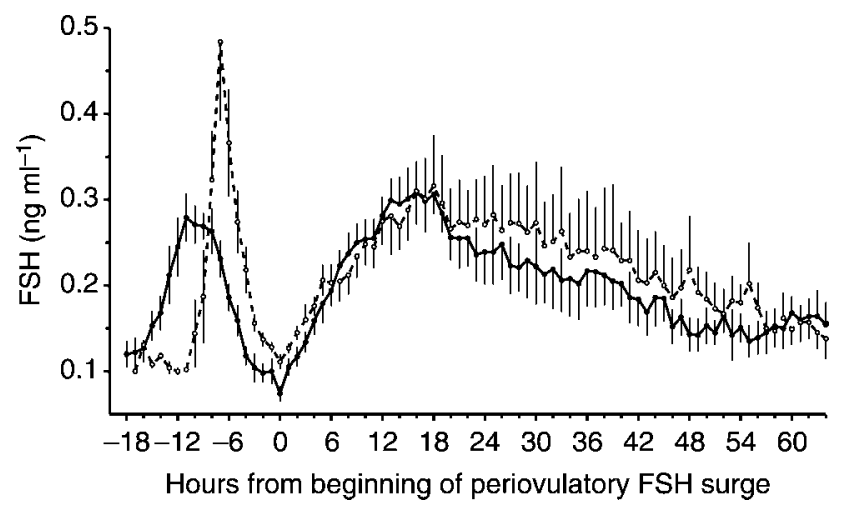

Figure 3 Concentrations (means \pm S.E.M.) of FSH for the preovulatory and periovulatory surges normalized to the beginning of the periovulatory surge in saline- $(\bullet, n=7)$ and $\mathrm{GnRH}-(0, n=6)$ treated heifers. 
the periovulatory FSH surge was not indicated in the group comparisons. When normalized to the peak of the periovulatory $\mathrm{FSH}$ surge, $\mathrm{LH}$ and estradiol concentrations following the preovulatory $\mathrm{LH}$ surge reached their lowest mean concentrations 18 and $20 \mathrm{~h}$ respectively after the mean for Nadir 2, and 4 and $6 \mathrm{~h}$ after the FSH peak (Fig. 4). Both LH $(P<0.001)$ and estradiol $(P<0.01)$ concentrations increased (hour effect) during the interval from the minimal value to $54 \mathrm{~h}$ after the peak. However, the first significant increase between the lowest mean and subsequent means did not occur until $37 \mathrm{~h}$ for estradiol and $20 \mathrm{~h}$ for $\mathrm{LH}$ after the FSH peak or $3 \mathrm{~h}$ after and $15 \mathrm{~h}$ before the mean hour of an $8.5 \mathrm{~mm} \mathrm{F1}$.

Ovulation from the dominant follicle of the pretreatment follicular wave occurred during the periovulatory FSH surge in every heifer. Ovulation was observed earlier $(P<0.01)$ after treatment in the GnRH group $(30.0 \pm 0.0 \mathrm{~h})$ than in the saline group $(50.0 \pm 3.4 \mathrm{~h})$. However, when the hour of ovulation was determined with reference to the hour of calculated onset of the preovulatory surge, there was no difference between the $\mathrm{GnRH}$ group $(30.0 \pm 0.0 \mathrm{~h})$ and the saline group $(29.9 \pm 1.3 \mathrm{~h})$.

\section{Periovulatory follicular wave}

The largest follicle in controls was 3.5 and $4.5 \mathrm{~mm}$ at $4.8 \pm 2.4$ and $13.9 \pm 2.2 \mathrm{~h}$ after the beginning of the periovulatory FSH surge (Nadir 2), based on the linear regression lines for individuals. Nadir 2 occurred before development of a $3.5 \mathrm{~mm} \mathrm{F1}$ in each heifer.
The emergence of $\mathrm{F} 1$ at $4.5 \mathrm{~mm}$ was detected earlier in the GnRH group than in the saline group (Table 2). The FSH concentrations during the periovulatory FSH surge reached the defined peak (Fig. 1) when the largest follicle was an average of $4.8 \pm 0.2 \mathrm{~mm}$. Treatment with $\mathrm{GnRH}$ did not affect $(P>0.10)$ the number of follicles attaining $\geq 5.0 \mathrm{~mm}$, growth rate of $\mathrm{F} 1$ between 4.5 to $8.5 \mathrm{~mm}$, or hour of the expected beginning of deviation as determined from the interval from Nadir 2 to an $8.5 \mathrm{~mm}$ F1. The follicle, as well as FSH data were combined for the two treatment groups for further analyses. The changes in diameters of F1 and F2 normalized to the hour closest to an $8.5 \mathrm{~mm} \mathrm{F1}$ (expected beginning of deviation) are shown in Fig. 5. The growth rates of $\mathrm{F} 1$ at $12 \mathrm{~h}$ intervals were not different $(P>0.1)$ among the $12 \mathrm{~h}$ intervals between -24 and $24 \mathrm{~h}$ relative to expected deviation. Within F2, the growth rates were not different among intervals until a reduction occurred $(P<0.01)$ between 0 and $12 \mathrm{~h}$ and between 12 and $24 \mathrm{~h}$ after the expected beginning of deviation.

The FSH profiles for the heifers with more vs fewer $5.0 \mathrm{~mm}$ follicles showed an interaction $(P<0.02)$, primarily due to lower FSH concentrations in the heifers with more follicles over approximately $12-48 \mathrm{~h}$ after Nadir 2 (Fig. 6). The heifers with more $5.0 \mathrm{~mm}$ follicles had significantly lower means at the FSH peak and at the beginning of the $\mathrm{FSH}$ decline and for the rate of $\mathrm{FSH}$ increase between Nadir 2 and the peak (Table 3). The differences approached significance for several other FSH end points in the same direction as for the significant differences (Table 3).

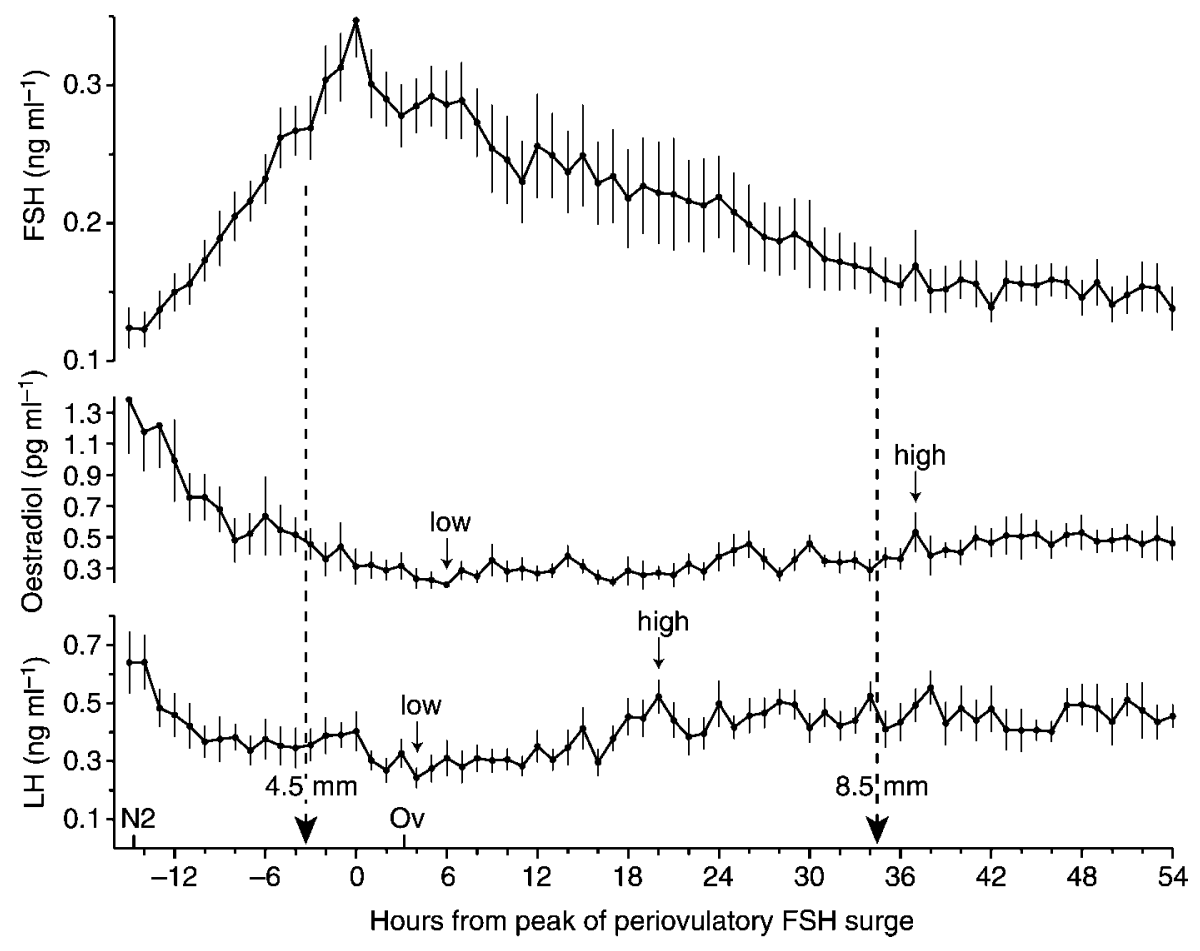

Figure 4 Concentrations (means \pm S.E.M.) of FSH, estradiol and LH normalized to the peak of the periovulatory FSH surge $(n=13)$. The vertical broken lines represent the mean hours of a $4.5 \mathrm{~mm}$ (emergence) and $8.5 \mathrm{~mm}$ (beginning of expected deviation) largest follicle, as taken from linear regression lines. N2 = mean hour of Nadir 2 or lowest concentration between the two FSH surges. Ov = mean hour of ovulation from the previous follicular wave. low = lowest mean; high $=$ first significantly higher mean. 


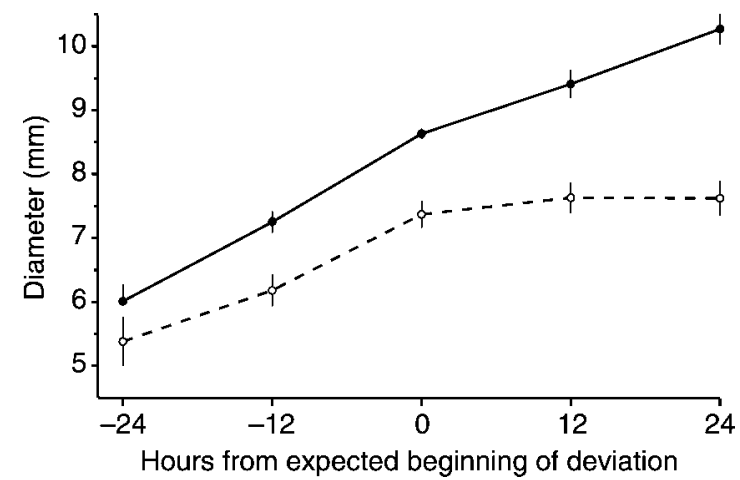

Figure 5 Diameters (means \pm S.E.M.) of the largest $(\bullet)$ and second-largest $(0)$ follicles normalized to the examination that the diameter of the largest follicle was closest to $8.5 \mathrm{~mm}$ (expected beginning of deviation, $n=13$ ).

Grouping of heifers into those with longer vs shorter intervals for growth of $\mathrm{F} 1$ from 4.5 to $8.5 \mathrm{~mm}$ did not result $(P>0.1)$ in a group effect or group-by-hour interaction for FSH concentrations (not shown), and there were no differences for any of the FSH end points (Table 3). However, the length of the 4.5 to $8.5 \mathrm{~mm}$ interval affected various aspects of the dynamics of F1 as shown (Table 3).

The heifers with identified FSH fluctuations superimposed on the periovulatory surge (Fig. 1a, C-g and j) compared with the heifers without superimposed fluctuations had a smaller area under the periovulatory FSH curve $(8.3 \pm 1.1$ vs $13.6 \pm 2.6 \mathrm{ng}, P<0.05)$ but had similar $(P>0.1)$ intervals from Nadir 2 to $8.5 \mathrm{~mm} \mathrm{F1}$ and from a $4.5 \mathrm{~mm}$ to an $8.5 \mathrm{~mm} \mathrm{F1}$.

\section{Discussion}

It is not known whether the GnRH-dependent preovulatory FSH surge has a physiological role. It does not appear to be necessary for ovulation of a dominant follicle and release of a viable oocyte (D'Occhio et al. 1998). However, it could be related to emergence of the first follicular wave. In investigating this in the current study we found in normal ovulating animals that the linear regression lines between a $4.5 \mathrm{~mm}$ and $8.5 \mathrm{~mm}$ F1 indicated that a $3.5 \mathrm{~mm}$ F1 occurred a mean of $4.8 \mathrm{~h}$ after the nadir between the preovulatory and periovulatory FSH surges, and this temporal relationship occurred in each heifer. The temporal coupling between a change in FSH and a change in follicles is close (Ginther et al. 1999), and on a temporal basis, emergence of the follicular wave can be attributed to the periovulatory FSH surge alone, supporting the concept that the periovulatory surge accounts for the emergence of the first follicular wave (Hypothesis 1). In this regard, the second follicular wave of the estrous cycle in cattle is preceded by a single FSH surge similar to the periovulatory FSH surge associated with the first wave, without a surge that can be considered similar to the preovulatory surge (Kulick et al. 2001). In addition, growth of follicles to $3.7 \mathrm{~mm}$ did not require an elevation in $\mathrm{FSH}$; the number of follicles $\leq 3.7 \mathrm{~mm}$ as determined histologically was not diminished when FSH was depressed by follicular fluid treatment (Lussier et al. 1994). This finding further diminishes the possibility that the preovulatory surge played a role in stimulating the wave. We also observed in the $\mathrm{GnRH}$-treated group that F1 follicles emerged earlier after the FSH nadir than in the normally ovulating heifers. This could be attributed to the

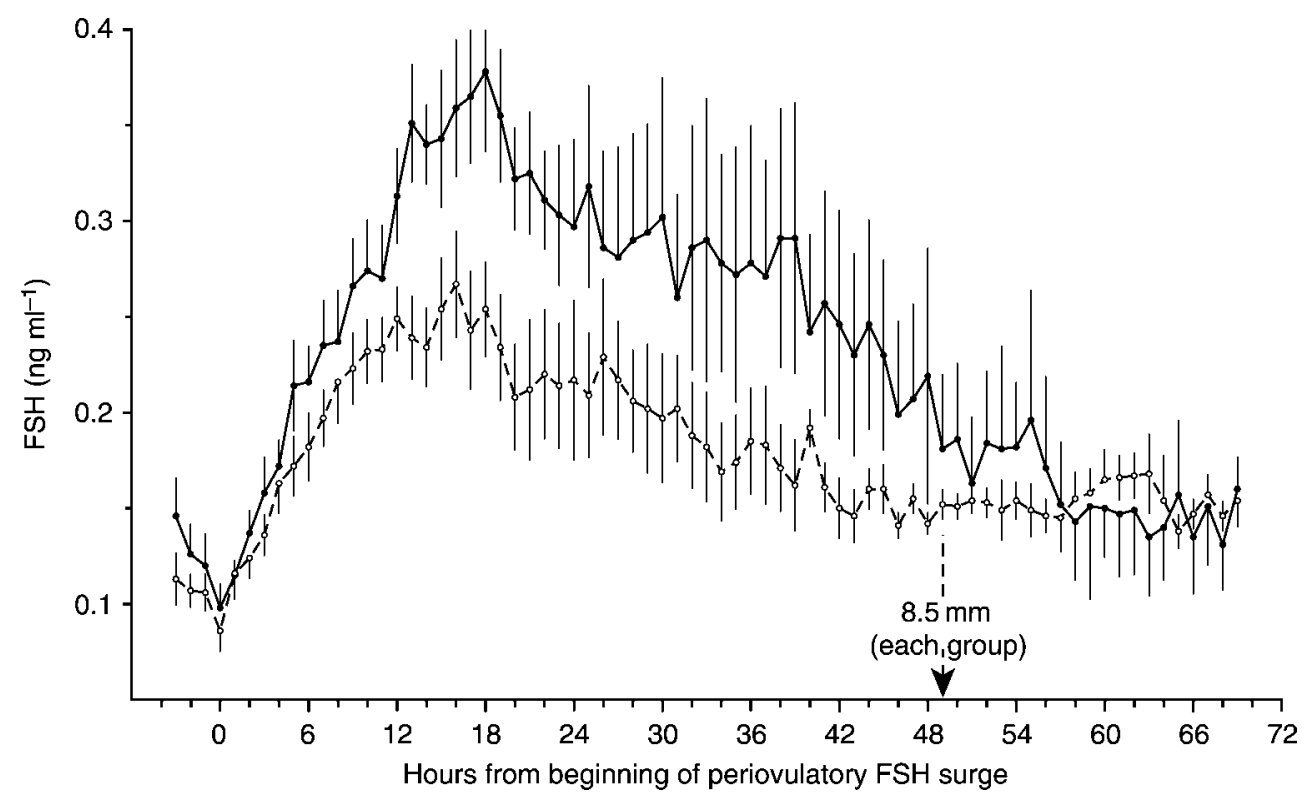

Figure 6 Concentrations (means \pm S.E.M.) of FSH in heifers with more $(\bullet, 9-17, n=7)$ vs fewer $(0,5$ or $6, n=6) 5.0$ mm follicles/wave. The vertical broken line indicates the mean hour of an $8.5 \mathrm{~mm}$ largest follicle as taken from linear regression lines $(49.2 \pm 2.9$ and $49.1 \pm 4.2 \mathrm{~h}$ for the two groups). 
GnRH-treated group having a 36\% higher FSH concentration at the $\mathrm{FSH}$ nadir that was detected between the two FSH surges.

The similarity in the minimal FSH concentrations (nadirs) that occurred before and after the preovulatory surge and after the periovulatory surge has not been shown previously. The depth and consistency in the nadir separating the two FSH surges indicate that each surge is distinct and may result from separate mechanisms. The $\mathrm{GnRH}$ treatment and its altered pattern of the preovulatory FSH surge did not affect the pattern of the periovulatory $\mathrm{FSH}$ surge. Furthermore, there was no indication that $\mathrm{GnRH}$ treatment increased the number of follicles growing to $5.0 \mathrm{~mm}$ in the periovulatory follicular wave, thus failing to confirm the results of an earlier report (Bodensteiner et al. 1996). Despite the failure to increase the variability in the FSH surge by $\mathrm{GnRH}$ treatment, there was extensive variation in the patterns of the periovulatory FSH surge among the 13 heifers, thereby facilitating testing of Hypothesis 2 (variation in the FSH surge is related to variation in the follicles). The variation in the FSH surge was demonstrated by the differences among surges in the presence and absence of distinctive peaks and in the interlude between defined peaks and the beginning of the FSH decline. In addition there were significant fluctuations in $\mathrm{FSH}$ concentrations in individual heifers as has been demonstrated previously using a cycle-detection program (Bergfelt et al. 1997). In the present study, FSH concentrations on average continued to decline after the expected beginning of deviation $(8.5 \mathrm{~mm} \mathrm{~F} 1)$, as previously reported (Ginther et al. 2001). However, the association between the average decline and the time of expected deviation was not a good representation for individuals; the nadir at the end of the progressive decline in individuals occurred before an $8.5 \mathrm{~mm} \mathrm{F1}$ in 5 of 12 surges (Fig. 1c-e, i and j), and an $8.5 \mathrm{~mm} F 1$ occurred during a superimposed fluctuation in three heifers (Fig. 1a, $\mathrm{d}$ and $\mathrm{j}$ ). These results indicated that a wide array of circulating FSH concentration profiles supported the growth of follicles and the selection of a single dominant follicle.

The variation in the periovulatory FSH surge was related to the variation in periovulatory follicular wave characteristics (Hypothesis 2) for the number of $5.0 \mathrm{~mm}$ follicles but not for follicular growth rate or time of occurrence of deviation. Increasing the FSH peak with exogenous $\mathrm{FSH}$ increases the number of $5.0 \mathrm{~mm}$ follicles (Gibbons et al. 1997). In the present study, there was no indication that higher endogenous FSH at any point during the surge was associated with the development of more follicles. On the contrary, heifers with more vs fewer $5.0 \mathrm{~mm}$ follicles had lower FSH concentrations during 12-48 h after the nadir between surges, a slower rate of FSH increase between the nadir and the peak, and lower FSH concentration at the peak. It is not reasonable that reduced FSH concentrations would cause development of more follicles, and it is concluded instead that the increasing numbers of $5.0 \mathrm{~mm}$ follicles had an increasingly depressive effect on
$\mathrm{FSH}$. In this regard, manipulation of the number of $5.0 \mathrm{~mm}$ follicles showed that the FSH decline was greater when multiple follicles were retained (Gibbons et al. 1997). In the present study, the FSH differences between heifers with more vs fewer follicles waned near the expected hour of deviation when only one follicle begins to control circulating hormone concentrations (Ginther et al. 2001).

The grouping of heifers with longer vs shorter intervals from a 4.5 to an $8.5 \mathrm{~mm}$ F1 did not disclose any relationships with the characteristics of the $\mathrm{FSH}$ surge. This finding seems consistent with the results of a recent study (Austin et al. 2002); experimentally altering the FSH pattern did not affect the diameter of the early dominant follicle (mean diameters 9.1-9.7 mm). Functional experiments involving the manipulation of $\mathrm{FSH}$ concentrations have demonstrated that low concentrations of FSH are necessary for deviation to occur (reviewed in Ginther et al. 2001). The present results are compatible with the concept that deviation is initiated when the most advanced follicle reaches a certain developmental stage in the presence of low FSH concentrations. This concept can now be expanded to further state that much variation is tolerated in the low or changing concentrations. That is, the occurrence of deviation at variable times relative to a designated reference point (e.g. beginning of the FSH surge, emergence of the wave) appears to be primarily related to the variation in the time expended by the F1 follicle in attaining the appropriate diameter or developmental stage and not the characteristics or variation in the FSH surge. This is an original conclusion.

In addition to the above results, it was found that exogenous $\mathrm{GnRH}$ resulted in higher peak concentrations and shorter duration of the induced vs natural preovulatory $\mathrm{LH}$ and $\mathrm{FSH}$ surges, without an effect on the area under the curve. These results are compatible with the concept that the entire store of gonadotropins was released by endogenous $\mathrm{GnRH}$, as well as by the injection of $\mathrm{GnRH}$. The similarity in the pattern of the preovulatory FSH surge with the pattern of the LH surge within each treatment group suggests that the two gonadotropins used similar mechanisms in the response to GnRH.

We found that estradiol concentrations were maximal at the peak of the LH surge and did not reach minimal concentrations until several hours after the periovulatory FSH peak. Decreasing concentrations of inhibin (Bleach et al. 2001, Kaneko et al. 2002), as well as estradiol, may decrease the negative feedback on pituitary FSH before the lowest concentrations of inhibin and estradiol are attained, thereby accounting for development of the periovulatory FSH surge. There was a significant effect of hour on circulating estradiol indicating that there was an increase in estradiol at some point between several hours and $54 \mathrm{~h}$ after the FSH peak. However, a significant estradiol increase from the minimal concentration was not 
detected until near the mean hour of deviation, minimizing the potential that estradiol had an FSH-depressing role throughout the FSH decline. However, an effect of the minimal concentrations of estradiol cannot be discounted. Inhibin A increases during the FSH decline and probably plays a major role in FSH suppression (Bleach et al. 2001, Kaneko et al. 2002).

The increase in concentrations of $\mathrm{LH}$ and estradiol relative to the hour of the expected beginning of deviation were similar to reported findings, and both hormones are believed to be involved in the deviation mechanism (for a review see Ginther et al. 2001). Although the increases in concentrations were significant, estradiol and LH concentrations at deviation were only 4 and $6 \%$ respectively of the concentrations at the natural preovulatory LH peak. Both hormones demonstrated apparent fluctuations in the means during the FSH decline, probably reflecting pulses that were too frequent to characterize by sampling every hour (Rhodes et al. 1995, Ginther et al. 1998). To address this question, more frequent sampling will be needed to characterize the temporal relationships among LH, FSH and estradiol fluctuations.

In conclusion, the periovulatory (second) FSH surge was more prominent in heifers with fewer $5.0 \mathrm{~mm}$ follicles in the wave than in heifers with more follicles. This result was attributed to a greater FSH-depressing effect when more $5.0 \mathrm{~mm}$ follicles developed. There was no indication that the extensive variation in the periovulatory FSH surge altered the growth rate of the largest follicle or the interval from the nadir at the beginning of the surge to deviation. The interpretation was that deviation is initiated toward the end of the FSH surge when the most advanced follicle is at an appropriate developmental stage and that the appropriate stage is reached independently of the characteristics or variations in the wavestimulating FSH surge.

\section{Acknowledgements}

This work was supported by the College of Agricultural and Life Sciences of the University of Wisconsin-Madison, USDA grants No. 9401080 and 0035203-9134, and the Eutheria Foundation, Cross Plains, Wisconsin. The authors thank Pharmacia for a gift of Lutalyse, the USDA Animal Health Program, A F Parlow of the National Hormone and Pituitary Program for gonadotropin assay reagents, and Susan Jensen for data analyses and figure preparation.

\section{References}

Austin EJ, Mihm M, Evans ACO, Ireland JLH, Ireland JJ \& Roche JF 2002 Effects of oestradiol and progesterone on secretion of gonadotrophins and health of first wave follicles during the oestrous cycle of beef heifers. Reproduction 124 531-541.

Bergfelt DR, Smith CA, Adams GP \& Ginther OJ 1997 Surges of FSH during the follicular and early luteal phases of the estrous cycle in heifers. Theriogenology 48 757-768.
Bleach ECL, Glencross RG, Feist SA, Groome NP \& Knight PG 2001 Plasma inhibin A in heifers: relationship with follicular dynamics, gonadotropins, and steroids during the estrous cycle and after treatment with bovine follicular fluid. Biology of Reproduction 64 $743-752$.

Bodensteiner KJ, Kot K, Wiltbank MC \& Ginther OJ 1996 Synchronization of emergence of follicular waves in cattle. Theriogenology $451115-1128$.

Bolt DJ \& Rollin R 1983 Development and application of a radioimmunoassay for bovine follicle-stimulating hormone. Journal of Animal Science 56 146-154.

Bolt DJ, Scott V \& Kiracofe GH 1990 Plasma LH and FSH after estradiol, norgestomet and $\mathrm{GnRH}$ treatment in ovariectomized beef heifers. Animal Reproduction Science 23 263-271.

Chenault JR, Kratzer DD, Rzepkowski RA \& Goodwin MC 1990 LH and FSH response of Holstein heifers to fertirelin acetate, gonadorelin, and buserelin. Theriogenology 34 81-97.

D'Occhio MJ, Sudha G, Jillela D, Whyte T, Maclellan LJ, Walsh J, Trigg TE \& Miller D 1998 Close synchrony of ovulation in superstimulated heifers that have a downregulated anterior pituitary gland and are induced to ovulate with exogenous LH. Theriogenology 49 637-644.

Fitzgerald BP, Afflack KJ, Barrows SP, Murdock WL, Barker KB \& Loy RG 1985 Changes in LH pulse frequency and amplitude in intact mares during transition into the breeding season. Journal of Reproduction and Fertility 79 485-493.

Gibbons JR, Wiltbank MC \& Ginther OJ 1997 Functional interrelationships between follicles greater than $4 \mathrm{~mm}$ and the folliclestimulating hormone surge in heifers. Biology of Reproduction $\mathbf{5 7}$ 1066-1073.

Ginther OJ, Bergfelt DR, Kulick LJ \& Kot K 1998 Pulsatility of systemic FSH and $\mathrm{LH}$ concentrations during follicular-wave development in cattle. Theriogenology 50 507-519.

Ginther OJ, Bergfelt DR, Kulick LJ \& Kot K 1999 Selection of the dominant follicle in cattle: establishment of follicle deviation in less than 8 hours through depression of FSH concentrations. Theriogenology 52 1079-1093.

Ginther OJ, Beg MA, Bergfelt DR, Donadeu FX \& Kot K 2001 Follicle selection in monovular species. Biology of Reproduction $\mathbf{6 5}$ 638-647.

Kaneko H, Noguchi J, Kikuchi K, Todoroki J \& Hasegawa Y 2002 Alterations in peripheral concentrations of inhibin $\mathrm{A}$ in cattle studied using a time-resolved immunofluorometric assay: relationship with estradiol and follicle-stimulating hormone in various reproductive conditions. Biology of Reproduction 67 38-45.

Kulick LJ, Kot K, Wiltbank MC \& Ginther OJ 1999 Follicular and hormonal dynamics during the first follicular wave in heifers. Theriogenology 52 913-921.

Kulick LJ, Bergfelt DR, Kot K \& Ginther OJ 2001 Follicle selection in cattle: follicle deviation and codominance within sequential waves. Biology of Reproduction 65 839-846.

Lucy MC \& Stevenson JS 1986 Gonadotropin-releasing hormone at estrus: luteinizing hormone, estradiol, and progesterone during the periestrual and postinsemination periods in dairy cattle. Biology of Reproduction 35 300-311.

Lussier JG, Matton P, Guilbault LA, Grasso F, Mapletoft RJ \& Carruthers TD 1994 Ovarian follicular development and endocrine responses in follicular-fluid-treated and hemi-ovariectomized heifers. Journal of Reproduction and Fertility 102 95-105.

Pursley JR, Mee MO \& Wiltbank MC 1995 Synchronization of ovulation in dairy cows using PGF2 $\alpha$ and GnRH. Theriogenology 44 915-923.

Rhodes FM, Fitzpatrick LA, Entwistle KW \& Kinder JE 1995 Hormone concentrations in the caudal vena cava during the first ovarian follicular wave of the oestrous cycle in heifers. Journal of Reproduction and Fertility $10433-39$.

SAS 1998 User's Guide: Statistics, 7th Version. Cary, NC: SAS Institute, Inc. 
Sunderland SJ, Crowe MA, Boland MP, Roche JF \& Ireland JJ 1994 Selection, dominance and atresia of follicles during the oestrous cycle of heifers. Journal of Reproduction and Fertility 101 547-555.

Taya K, Kaneko H, Watanabe G \& Sasamoto S 1991 Inhibin and secretion of FSH in oestrous cycles of cows and pigs. Journal of Reproduction and Fertility 43 (Suppl) 151-162.

Turzillo AM \& Fortune JE 1990 Suppression of the secondary FSH surge with bovine follicular fluid is associated with delayed ovarian follicular development in heifers. Journal of Reproduction and Fertility 89 643-653.
Yoshioka K, Suzuki C, Arai S, Iwamura S \& Hirose H 2001 Gonadotropin-releasing hormone in third ventricular cerebrospinal fluid of the heifer during the estrous cycle. Biology of Reproduction $\mathbf{6 4}$ 563-570.

Received 20 February 2003

First decision 27 March 2003

Revised Manuscript Received 9 September 2003

Accepted 23 September 2003 